\title{
The application of computational fluid dynamics to environmental health risk
}

\author{
M. P. Straw \& R. Harwood \\ Fluent Europe Ltd, UK
}

\begin{abstract}
Computational Fluid Dynamics (CFD) is a technique utilising numerical methods to simulate fluid flow, heat transfer and chemical reactions for the analysis of systems and processes. CFD is widely applied in many industries. In an industry sector such as environmental health risk that encompasses a wide range of issues, CFD techniques can provide significant benefit in many areas.

This paper presents an introduction to CFD modelling techniques and their application to a number of relevant issues including the modelling of pollution producing processes, pollution reduction and transport as well as hazard analysis.

The paper concludes with case studies demonstrating how CFD modelling has provided direct environmental, health and safety, financial and knowledge benefits to the solution of a number of pertinent examples.
\end{abstract}

\section{Introduction}

\subsection{What is Computational Fluid Dynamics?}

Computational Fluid Dynamics (CFD) utilises numerical methods to solve the governing equations of fluid dynamics - the equations describing the conservation of mass, momentum and energy.

There are many potential applications for CFD within the field of environmental health risk. Using CFD, it is feasible to simulate many fluid flow process including those that produce pollutants (for improving efficiency), pollution reducing techniques, pollutant transportation and dispersion as well as hazard analysis applications. This paper by no means provides details of every situation to which CFD can be applied, however it aims to highlight the broad scope of applicability. The paper concludes with three pertinent case studies.

The Fluent CFD software was used exclusively for the modelling work described in this paper. 


\section{CFD application to environmental health risk}

In the last decade the CFD service industry has developed significantly which is mainly attributable to the increase in computing power and the associated number of available software packages.

Industries in which CFD is currently widely utilised include aerospace, automotive, nuclear, oil and gas, power generation, chemical and process, HVAC, electronic component cooling and environmental applications amongst others. All of the aforementioned industry sectors have significant potential for utilising CFD within environmental health risk applications (if this is not already the case).

\subsection{Modelling of pollution production and reduction}

Pollution is produced through a myriad of processes and can take many different forms e.g. solid or liquid particulates and gaseous substances. Many processes that lead to the production of pollutants or hazardous substances can be simulated using CFD. This provides further understanding of the phenomena involved enabling improvement of component or system design to reduce the level of pollutant produced.

The power industry is one of the world's largest producers of ambient air pollution through the combustion of fossil fuels. In recent years the reduction of levels of oxides of nitrogen $\left(\mathrm{NO}_{\mathrm{x}}\right)$ has been a major driver in the design of coal combustion systems. CFD has been an integral tool in many companies involved in burner design. Figure 1 shows a Fluent CFD model of a low $\mathrm{NO}_{\mathrm{x}}$ coal burner.

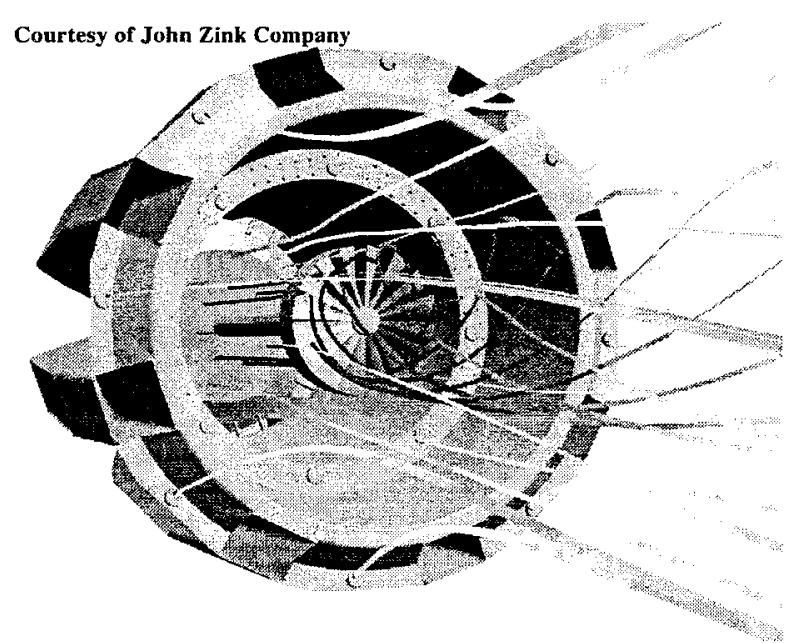

Figure 1: Fluent CFD simulation of a lox $\mathrm{NO}_{\mathrm{x}}$ burner 
As well as reducing the pollution produced during industrial processes, CFD is also applied in the removal of pollutants from exhaust gases and effluent. The removal of particulate matter from effluent streams to be released into the environment has been modelled using CFD to assess and improve process efficiency.

Techniques such as particulate scrubbers, electrostatic precipitators and baghouses have been modelled successfully. Cyclonic devices, often used in process industries for removal of particulates from fluid streams, are commonly modelled and CFD has lead to numerous design enhancements of individual cyclones. Figure 2 shows pathlines of particulates through a typical cyclonic device.

In the treatment of water, screens and filters are commonly used. CFD modelling can assist with the design, or provide remedial strategies, for loading rate equalisation. Coagulation and flocculation processes can be modelled. In these processes good mixing of the influent and the coagulant is essential. A CFD model can be used to investigate the mixing driven by different impeller types and to identify optimum placement of the mixers. The multiple phase modelling capabilities of the Fluent software can be used to assess the performance of settlement and clarification tanks. CFD simulations can be carried out to rapidly determine the residence time distribution curves for contact tanks. In addition, user specific models can be implemented to study the effects of the decay in concentration of an injected tracer with time.

Most of the common treatment processes within a wastewater treatment works can be modelled using CFD in some way to yield direct benefits for the design or process engineer. These include sedimentation tanks, aeration tanks, clarifiers and filters.

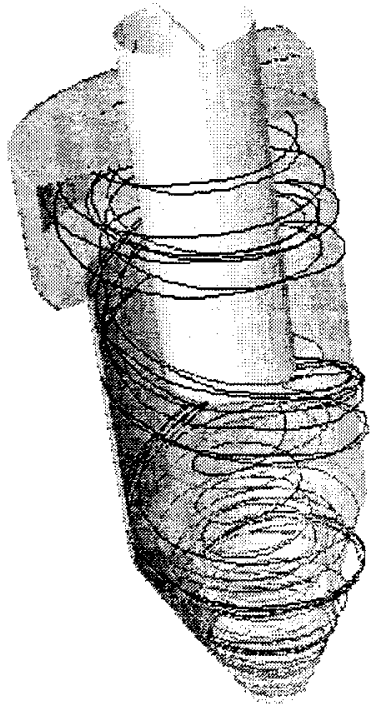

Figure 2: Particle tracks through an axial cyclone 


\subsection{Modelling of pollutant transport and dispersion}

Reducing the levels of pollution emitted is the main aim in any pollution producing process however, in many cases complete removal is not realistic or practical. It is therefore important to have the capability to understand what happens to pollutants released into the relevant environment. For the purposes of an air or water quality assessment the environment could be defined as the atmosphere, an enclosed or indoor space, river or reservoir.

CFD modelling of releases into rivers and reservoirs or into the atmosphere can be undertaken to understand plume visibility and short or long range dispersion. Figure 3 shows a Fluent CFD model of the plume from the cooling tower of a power station.

Indoor air quality is a common issue in many situations. CFD is a common tool in ventilation system design and analysis. It is used to predict the relative comfort levels experienced by a rooms inhabitants (whether human, animal or plants) and to assess the locations of air intakes and vents to ensure air quality and ventilation is satisfactory.

\subsection{CFD in hazard assessment}

It is important to ensure that working environments are assessed for health and safety. In the offshore industry, for example, it is necessary to ensure that sufficient ventilation is provided through an installation such that any potential release is dispersed as safely as possible. It is also important to ensure that helideck operations are unaffected by any exhaust gases released.

CFD can be applied in the prediction of potential fire and smoke movement and in the assessment of health and safety issues in laboratory or industrial environments. Figures $4 \mathrm{a}$ and $\mathrm{b}$ demonstrate Fluent CFD software being utilised to simulate the movement of smoke in a residential structure and the removal of ammonia from a laboratory respectively.

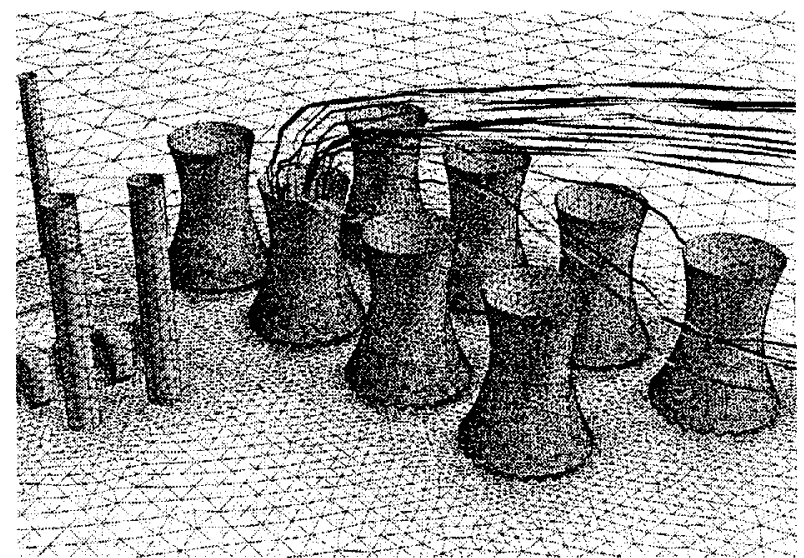

Figure 3: Dispersion from cooling towers 


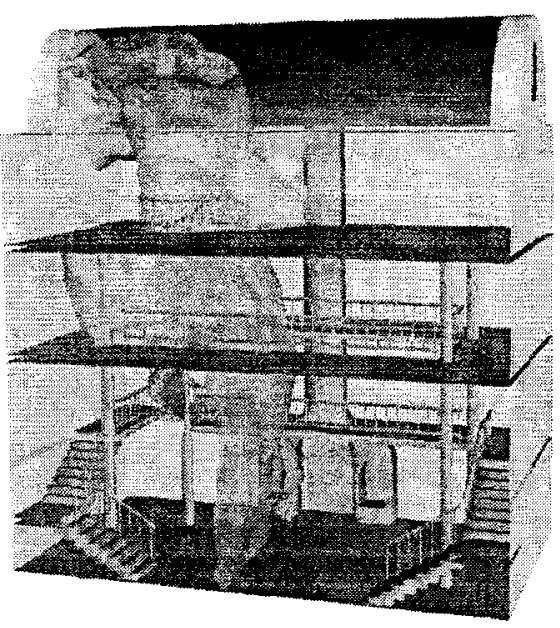

a) Smoke movement in a house

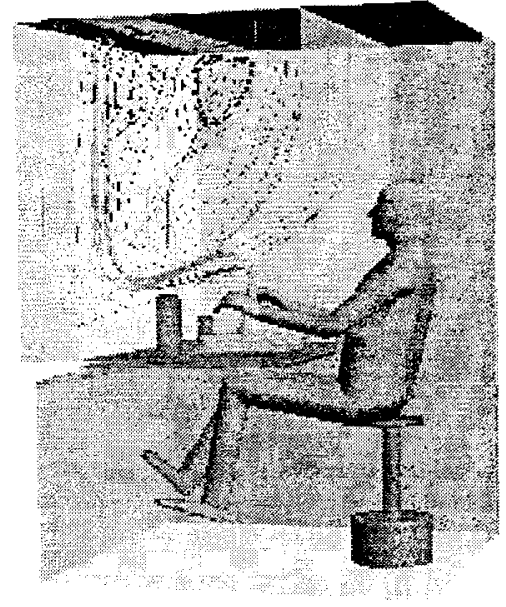

b) Ammonia removal from a laboratory Figure 5: Typical applications of Fluent CFD in hazard analysis applications

\section{CFD application case studies}

The following case studies aim to demonstrate where the Fluent CFD software has been applied to a number of situations involving environmental health risk issues. Analogies with many other applications can clearly be drawn.

\subsection{Offshore health and safety investigation - ventilation}

\subsubsection{Project description}

The latest Health and Safety Executive prepared guidelines for design, construction and certification of offshore installations [1] were updated in light of Lord Cullens Report on the Piper Alpha disaster [2]. They state the minimum air flow rates that any offshore installation must experience due to natural ventilation along with remedial measures that must be put in place if these are not met i.e. provision of mechanical ventilation.

Trident Consultants Far East required Fluent to produce a CFD model to predict the natural ventilation of a proposed processing platform located in the Persian Gulf and to provide guidance for the location of mechanical ventilation for regions where ventilation guidelines were not satisfied.

\subsubsection{CFD analysis}

The CFD model involved building the main processing platform and a smaller platform joined to the main structure via a bridge in a 'virtual wind tunnel' $2 \mathrm{~km}$ in length and width and $200 \mathrm{~m}$ in height. All equipment with a minimum dimension of $0.5 \mathrm{~m}$ or larger was modelled explicitly. Regions where groups of small equipment was located, such as pipe bundles, were simulated as porous zones. 
The wind driven flow field around and within the structure was predicted to assess the natural ventilation through the main platform. Figure 6 shows the geometry of the CFD model of the two platforms. In the case where the wind approached the main platform from the smaller platform, the upstream structure produced a velocity deficit region in its lee. This reduction in velocity had an adverse effect of the natural ventilation of the main platform. Figure 7 shows contours of the regions on the central processing deck where natural ventilation was potentially poor.

\subsubsection{Project outcome}

The CFD study concluded that the natural ventilation on the main platform would be sufficient such that for $95 \%$ of the year, minimum ventilation rates would be met over the majority of the platform. However, a number of small regions in, particularly enclosed areas, required supplementary mechanical ventilation.

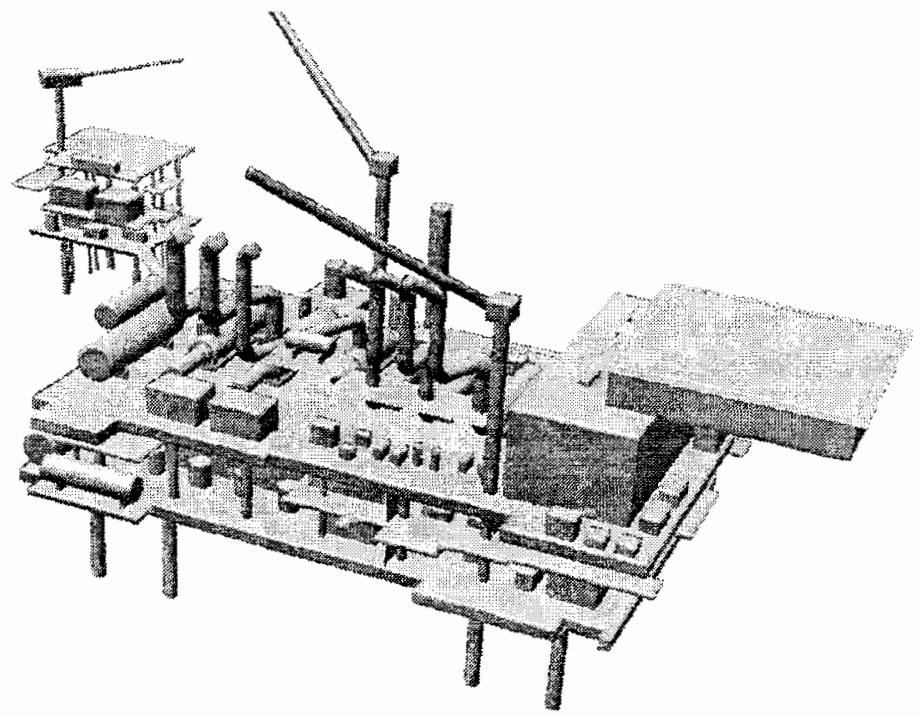

Figure 6: Fluent CFD model of offshore platform 


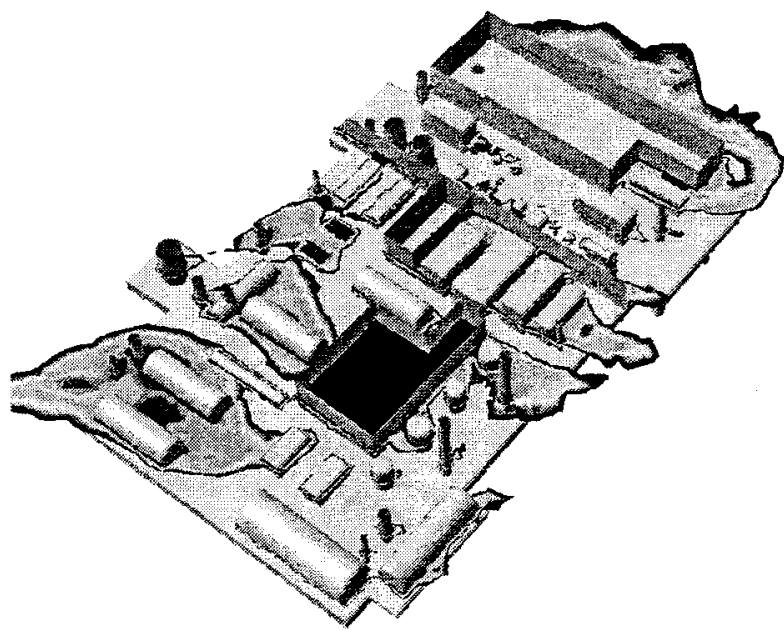

Figure 7: Regions on central deck of platform displaying poor ventilation

\subsection{BP Vietnam oil platform - helicopter operations investigation}

\subsubsection{Project description}

For offshore helicopter operations, guidelines [3] state that ambient temperature increases of greater than $2^{\circ} \mathrm{C}$ in the flight path or landing area become an operational issue. Helicopters engulfed by hot gas plumes may suffer a loss of lift which may result in an uncontrolled descent and heavy landing. It is therefore necessary to assess if there is the possibility of particular wind speeds or wind directions leading to such increases in ambient temperature.

A safety study of a BP platform to be constructed in the waters off Vietnam required CFD analysis of the effects of hot turbine exhaust gases on the ambient air temperature in the vicinity of the helideck.

\subsubsection{CFD analysis}

Fluent CFD software was used to produce a model of the platform and surrounding environment. The atmospheric boundary layer was simulated and the wind driven flow around and within the platform predicted to find any temperature rise in the vicinity of the helideck due to the exhaust emissions.

The model was solved for a range of wind speeds and directions to establish how often the helideck would be exposed to temperature rises greater than the $2^{\circ} \mathrm{C}$ threshold.

Figure 8 shows pathlines from the turbine exhausts produced from one of the simulations. The region enclosed by the pathlines shows where the ambient temperature is at least $2^{\circ} \mathrm{C}$ greater than the ambient temperature.

\subsubsection{Project outcome}

Using CFD techniques, it was possible to model many different conditions within a matter of weeks and provide immediate feedback to the design team. It is necessary to prove safety in order to meet the standards of the legislative body for the oil and gas industry. 


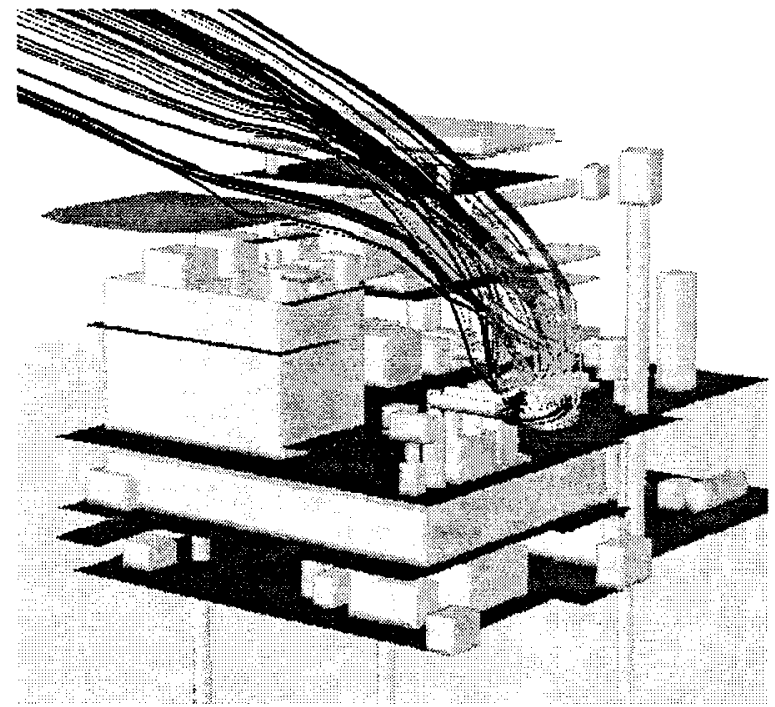

Figure 8: Region over helideck with unacceptable temperature rise

\subsection{The Johnston Pipes Ltd StormFox Combined Surface Overflow (CSO) Chamber}

\subsubsection{Project description}

In the UK, most urban drainage networks are combined, i.e. domestic and industrial waste is conveyed in the same sewer. Overflow systems, or relief structures, are designed for storm conditions during which the sewer capacity is exceeded. Discharges from these combined sewer overflows (CSOs) have been identified as one of the major causes of urban water course pollution.

The Fluent CFD software has been used effectively to simulate the hydraulic and particle retention efficiency performance of designs of extended stilling pond, high side weir and hydrodynamic separator CSO chambers [4]. In response to the identified need for an effective solution to the problem of CSO discharges, Johnston Pipes Ltd produced a new design of chamber called the StormFox. The StormFox consisted of an enlarged pipe built along the line of the existing sewer that contains two longitudinal spill weirs protected by scumboards. Benching was included to prevent sediment deposition and to form a dry weather flow channel. A cross section through a model StormFox is shown in Figure 9.

\subsubsection{CFD analysis}

Johnston Pipes Ltd used CFD to streamline and fast track the design process. The Fluent software was used to optimise the design of the chamber in terms of particle retention efficiency. CFD simulations were carried out to determine the effect of changes to the benching angle, the weir height, the scumboard location and the use of storage and stilling zones on the ability of the chamber to retain particles within the sewer system. Velocity vectors in a downstream cross section of the StormFox are shown in Figure 10. 


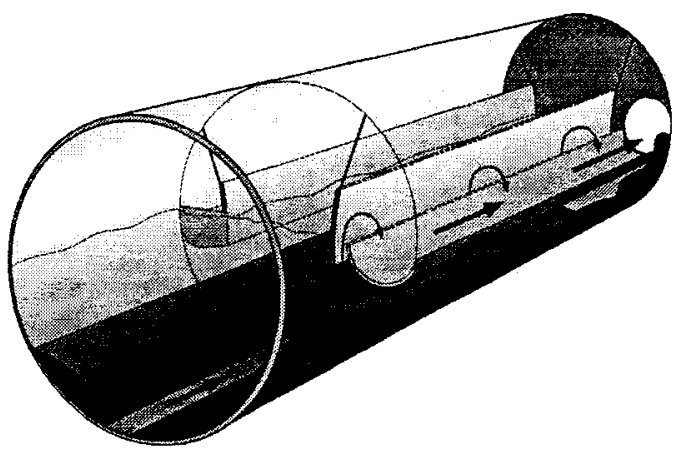

Figure 9: A model StormFox chamber

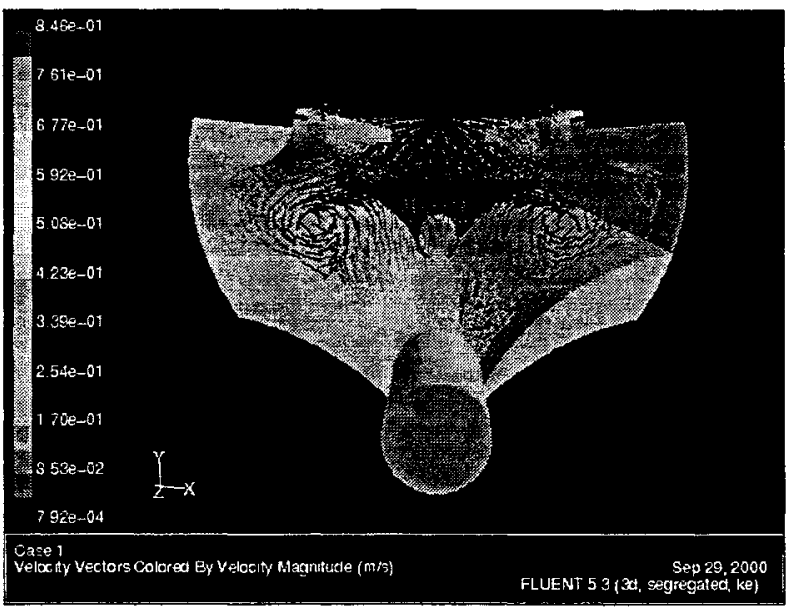

Figure 10: Example of CFD flow pattern results in StormFox

\subsubsection{Project outcome}

The particle tracking routine of the Fluent software was used to predict the trajectories of a statistically significant number of $6 \mathrm{~mm}$ diameter particles injected at the chamber inlet. By recording the final destination of each particle, either spill flow, continuation flow or trapped in the chamber the ability of each chamber configuration to retain particles within the sewer system was determined. Using this approach the optimum geometrical configuration was selected and proposed as the StormFox standard design.

The results of an independent performance assessment concluded that the chamber offered significant separation of solids [5] and the chamber is now being considered for use by many of the water utility companies. 


\section{Summary}

This paper has presented an introduction to CFD and has described some of the areas where CFD can be applied within the field of environmental health risk. The aim of the paper was to demonstrate practical applications where CFD has been successfully implemented to provide design changes or clarification with respect to health and safety or environmental concerns and legislation. Obviously it is not possible to cover all aspects in this field to which CFD can be applied however, the case studies outlined have many clear analogous applications in a myriad of industries.

\section{References}

[1] Health \& Safety Executive, Offshore Installations: Guidance on Design, Construction and Certification, $4^{\text {th }}$ Edition, HMSO, London, 1990.

[2] The Hon. Lord Cullen, The Public Enquiry into the Pipa Alpha Disaster, CM1310, HMSO, London, 1990.

[3] Civil Aviation Authority, CAP437: Offshore Helicopter Landing Areas guidance on standards, CAA, London, 1998.

[4] Harwood, R., Saul, A.J., The Influence of CSO Chamber Size on Particle Retention Efficiency Performance. Proc. $8^{\text {th }}$ Int. Conf. On Urban Storm Drainage, Sydney, Australia, pp 1-9, 1999.

[5] Saul, A.J., Skipworth,P.J., Johnston Pipes Ltd StormFox CSO Chamber Results of Full Scale Testing at the National CSO Test Facility, University of Sheffield report to Johnston Pipes Ltd, 2000. 